\section{NATIONAL EDUCATION POLICY 2020: EMPOWERING TEACHER EDUCATION}

KEY WORDS: NEP 2020,

Teacher Education, Integrated Teacher Education Program (ITEP), NCTE, TEIs

\title{
Anshuman
} Tiwari

Junior Research Scholar Centre of Education Indian Institute of Teacher Education, Gandhinagar, Gujarat.

The Government of India released the National Education Policy 2020 (NEP 2020) in July 2020, 34 years after the last national policy was released in 1986. Momentous and essential changes in the education system is proposed in NEP 2020, which is rooting and getting operationalised in the country, including Teacher Education. This paper discusses reflection on the steps suggested by NEP 2020 to improve the quality of Teacher Education and the reforms considered necessary as per the futuristic need. It also talks about how to equip the future teachers with transforming Teaching Learning process with innovative pedagogy. As it is known that research and development has very vast effect on the growth of any country, NEP 2020 focuses on research in the field of educational psychology, philosophy, sociology etc. with integration of science and technology. It also advocates the designing of National Curriculum Framework for Teacher Education (NCFTE). Nep 2020 emphases on the multidisciplinary inputs, and education in high-quality content as well as pedagogy. This paper also focuses on how the Integrated Teacher Education Program (ITEP) will be implemented in multidisciplinary institutions and universities and how this ITEP, the 4-year Bachelor's Degree Integrated Teacher Education Program in different stream will, enhance the quality of teachers in the education system. It is also discussed in the paper that how Nep 2020 also focuses on improving high quality of research with the help of financial assistance in the field of Teacher Education.

\section{Conceptual Framework:}

Effectiveness becomes an important condition for any country to adopt varied education systems putting into consideration to their individual traditions, cultural differences and their multistage process employed at school and higher education level. The union cabinet of India has approved the updated and much thought National Education Policy 2020 on 29th July 2020, putting into forefront the aim of India's future education system and putting significant basis for replacing the outgoing policy of NEP 1986. The newer policy document aims at stronger foundation keeping in view the both rural and urban population of modern India and strengthening the vocational training and elementary education at all possible level in the curriculum framework. The NEP 2020 looks to ameliorate of the education system of the country. The policy also exits the idea of Teacher Education, being solely limited to Teacher Training in the effort of lacing concept into a deeper regime of acquiring the required abilities, pedagogical skills, content training and prolific approach towards teaching learning imparting them an expertise much needed from beneficiaries of such courses of Teacher Education to build more capable and professionally responsible educators. It also puts to view the oral development of Prospective Teachers into undertaking a significant change in their attitude, personality traits, regimes, values and professional ethics. The NCTE Act, Sec. 2 (1) of 1993 states: "Teacher Education means programs of education, research or training of persons for equipping them to teach at pre-primary, primary, secondary and senior secondary stages in schools and includes non-formal education, part-time education, adult education and correspondence education." Any education system has to put into front the concept of Teacher Education significantly on the sole basis, the Teacher Education is a fundamental function of any such system, keeping into view the teacher being rendered out of such systems (primarily in the background of India) be well established and knowing of the culture, traditions, geographical conditions, ethics, ethos, and traditions culture along with an equally skill full hand trained for the latest advancement both in education technology and pedagogy.

\section{Teacher Education in Indian Context:}

Before NEP 2020, the Indian system was badly affected by the classical value-based education hits of backlogs in the form of new education technology. It is to be understood that no imported framework can produce the desired results in the Indian sub-continent. India has to put emphasis on practical and grounded educational system for teacher education clubbing together a great assortment of an ancient Indian values and modern research. An example of these reforms can be understood through the recent change in in the Delhi government schools. So, important models although beneficial in nature are not practically implacable in the Indian context. The amalgamation of ancient Indian wisdom and contemporary research can bring about a judicious change in educational quality.

\section{Forthcoming Standpoints of Teacher Education as per NEP 2020:}

Bachelor's degree Teacher Education Program \& its Regulations: As per NEP 2020, current TEIs will be given criteria to convert by 2030 to offer and start 4-year Integrated Teacher Education Program (ITEP). The minimal degree of qualification will be remained a bar by 2030 being the ITEP. The ITEP will have a measure holistic upliftment through specialization in language, history, music, mathematics, computer science, chemistry, economics, art, physical education, etc. Not only research will be benefited but Teacher Education will be more grounded in history, science, psychology, sociology, early childhood care and education, foundational literacy and numeracy, knowledge of India and its values/ethos/art/traditions etc. (NEP 2020).

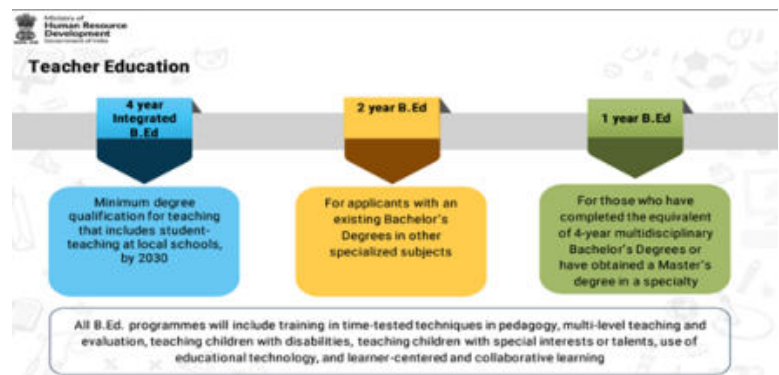

Figure - 1. Bachelor's Degree Teacher Education Program as per NEP 2020

Note: (Adopted from National Education Policy 2020. MoE, New Delhi: Government of India)

As per the Justice Verma Committee Recommendations (Recommendation Number-3), "The Teacher Education should be a part of Higher Education and the duration of the teacher education program need to be enhanced" has been taken into consideration for recommending the Teacher 
Education courses by NEP 2020. As per the recommendations of NEP 2020, the HEIs offering 4-year integrated B.Ed. may also run a 2-year B.Ed., for pupils who have previously received a bachelor's degree in a specific subject. A l-year B.Ed. may also be offered for entrants who have received a 4year undergraduate degree in a specialized subject as shown in figure 1.

\section{Prominent features of Integrated Teacher Education} Programme (ITEP): An innovative and necessary change:

1. ITEP shall be offered directly after $(5+3+3+4)$ of schooling, due to this the actual candidates wanted to build his/her carrier in Teacher Education or school education can enter at very early stage and can be moulded under the leadership of trained and excellent educators.

2. ITEP program will be able to prepare the good teachers who can adjust with the necessary changes as per NEP 2020 in the school curriculum.

3. The teachers prepared by ITEP courses will have broad and multidisciplinary subject knowledge through which they can guide students to choose their stream related to their area of professional interest as per the individual need of the each and every child.

4. ITEP also provide both content as well as pedagogic skills to nurtures the sharp brain of the country.

5. As per NEP 2020 ITEP will be the minimal educational qualification for school teachers because of that ITEP Program will be started in education department of universities at very large section in higher education which will ultimately lead to the huge requirement and vacancy in Teacher Education. From this we can implies that NEP 2020 also provide a large quantity of carrier opportunity in the field of Teacher Education in upcoming year.

6. As per NCTE (Norms and Standards for ITEP Program), Regulations, 2014 Gazette Notification No. 509, dated 22.10.2021 published on 26.10.2021 "ITEP shall be implemented in a phase wise manner starting from piloting in multidisciplinary HEIS/TEIs and thereby country wide expansion as per NEP 2020 timeframe and the exit system shall be applicable in ITEP as finalised in the National Higher Education Qualification Framework by UGC aligned with NEP 2020". This multiple exit and entry system will also empower Teacher Education as it gives liberty of speed, liberation from fear of wasting time, and convenience to the students.

\section{Promotion of Research \&Development inTeacherEducation:}

Research is the backbone for the whole sum development of any country. It has been observed that the countries those have given importance to the research work have been developed very rapidly. Unfortunately,

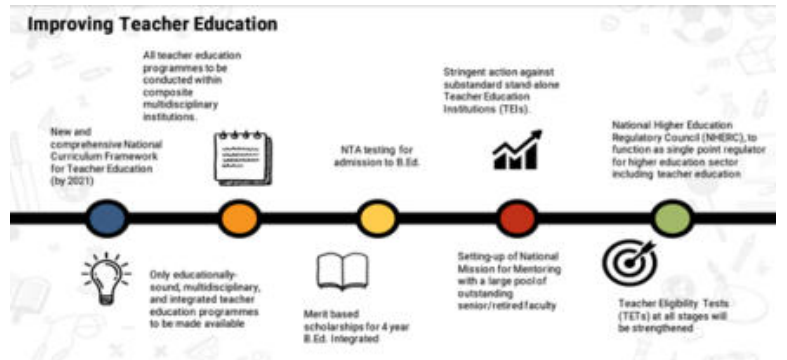

Figure -2. Development in Teacher Education

Note: (Adopted from National Education Policy 2020. New Delhi: Government of India)

Currently India spends only $0.69 \%$ of its Gross Domestic Product for the Research \& Development which is very low in comparison to the other developed countries which are growing very swiftly with the help of Research \&
Development. This NEP 2020 also prominence on the elevation of research and development in the field of Education. NEP 2020 also proposed a National Research Foundation for the preferment and development of quality research in the different field of education. The main aim of $\mathrm{NRF}$ will be, funding and providing grants for the individuals, colleges and universities for carryout the quality research in the different field. NRF will facilitates the research at academic institutions and work as a bridge between researchers and government funding agencies to improve research work. NEP 2020 also accent that any research scholar who are pursuing Ph.D. in any discipline must have to acquire some credit courses of Teacher Education and small courses related to Teaching Learning process. The new and comprehensive National Curriculum Framework for Teacher Education (NCFTE 2021) will be formulated by the National Council for Teacher Education (NCTE) in consultation with the National Council of Educational Research and Training (NCERT). National Professional Standard for Teachers (NPST) and National Mentoring Mission (NMM) Proposed by NEP 2020 for the betterment of school education has also been drafted by NCTE and will be finalised soon. A brief flow chart for the improvement of quality of Teacher and Teacher Education suggested by NEP 2020 is shown in Figure 2.

\section{CONCLUSION:}

National Education Policy 2020 focuses on an educational system that contributes to an equitable and vibrant knowledge society by providing high quality education to all. It also focuses on empowering Teacher Education Programs and improving the quality and teachers of tomorrow. On the recommendation of NEP 2020 NCTE introduced a new fouryear integrated teacher education program (ITEP), B. A/B.Com./ B.Sc. B.Ed. program which aims to prepare committed, responsible and professional teachers. This program is proposed to effect in the ordinary swing in teacher preparation. This is unique, innovative and dedicated program planned with fundamental amalgamation of pedagogy and content laterally through continual rendezvous with liberal discipline of knowledge and field of education. NEP 2020 envisaged an innovation and formulations of standard setting regulations for Teachers and Teacher Educators. NEP 2020 also emphases on enhancement of research and development in the field of Teacher Education and modifying the institution into multidisciplinary courses offering institution. NEP 2020 will be proved to be the milestone of education system of India in upcoming future.

\section{REFERENCES}

1. Bella Joseph (2013) Teacher effectiveness and professional competency among higher secondary school teachers in Kottayam district, Kerala, Sodhganaga. Retrieved on December 05, 2021 from: https://shodhganga. inflibnet.ac.in/bitstream/10603/8678/10/10_chapter\%201.pdf

2. Best J.W.(1970), Research in Education, Prentice-Hall of India,New Delhi.

3. Bharadwaj B.P (2016) DEPARTMENT OF TEACHER EDUCATION National Council of Educational Research and Training Syllabus for Bachelor of Education (B.Ed.) Program Retrieved on December 11,2021 from: http://www.ncert.nic.in/departments/nie/dtee/activities/pdf/syllabus bed.pdf

4. Brown G. \& Atkins M. (1988), Effective Teaching in Higher Education, Methuen, London, 1988.

5. Buch M.B.ed.(1991), Fourth Survey of Research in Education, NCERT

6. Buch M.B.,ed. (1987), Third Survey of Research in Education, NCERT.

7. Chakrabarti M. (1998), Teacher Education; Modem Trends, Kanishka Publishers, Distributors, New Delhi.

8. Dunkin Michael J. (1987), The International Encyclopedia of Teaching and Teacher Education, 1987.

9. Forzani,F.M. (2014). Understanding "core practices" and "practice-based"teacher education:learning from the past.Journal of Teacher Education,65(4),357-368.

10. Friedrich,D. (2014). "We bought it upon ourselves": university-based teacher education and the emergence of boot-camp-style routes to teacher certification. Education Policy Analysis Archives, 22(2), 1-17.

11. Garcha, S. P. (2014). Two-year B.Ed. and M.Ed.: A new Challenge paper published in a proceedings of seminar book Transforming Teacher Education in Changing Scenario, ISBN978-93-80748-85-6 NCTE (2014). Garrett H.E. (1961), Statistics in Psychology and Education, Allied Pacific,Bombay.

12. Gay L.R. (1987), Educational Research, Competencies for Analysis and Application, Merril Publishing Company, London.

13. GOI (2019) NATIONAL COUNCIL OF TEACHER EDUCATION NEW DELHI Retrieved on October 14, 2021 from: http://ncte.gov.in/ Website/ PDF/ ANNOUNCEMENT/Gazette\%20Notification $\% 20$ of $\% 20$ NCTE $\% 20$ Regulatio ns\%20(ITEP).pdf

14. Grossman, P., Mammerness, K. \& McDonald, M. (2009). Reflecting teaching, 
re-imagining teacher education. Teachers and Teaching: Theory and Practice, 15(2), 273-289.

15. Ingyarson, L. (2002). Development of a national Standards Framework for the Teaching Profession. Australian Council for Educational Research.

16. Member-Secretary, National Council for Teacher Education (2010) National Curriculum Framework for Teacher Education New Delhi Retrieved in August 2021 from http://ncte-india.org/ncte_new/pdf/NCFTE_2010.pdf

17. MHRD (2012). Vision of Teacher Education in India: Quality and Regulatory Perspective-Report of the High-Powered Commission on Teacher Education Constituted by the Hon'ble Supreme Court of India. New Delhi: Education Constituted by the Hon'ble Supreme Court of India. New Delhi: MHRD, Government of India.

18. MHRD (2019). The National Policy on Education. New Delhi: Ministry of Human Resource Development.

19. MHRD (2020).National Education Policy 2020.New Delhi: Government of India.

20. NCTE (2016). Upanishads: Messages for Teachers and Teacher Educators. New Delhi:National Council for Teacher Education.

21. NCTE (2018). CURRICULUM FRAMEWORK FOR THE NCTE TWO-YEAR B.ED. PROGRAMME Retrieved on August 14, 2021 from http://ncteindia.org/ Curriculum\% 20Framework/B.Ed\%20Curriculum.pdf

22. NCTE (2018). NCTE (Recognition, Norms and Procedure) Amendment Regulations, 2018. New Delhi: National Council for Teacher Education, Government of India. 